\title{
O AVESSO ATRAVÉS DO ESPELHO: ESPACIALIDADES MÚLTIPLAS E TRANSIÇÕES IDENTITÁRIAS
}

Ana Carla Bellon (UERJ)

As teorias têm sempre um caráter provisório. Cada uma alimenta sua própria destruição e cria condições para que surja uma nova teoria que a torne caduca.

Claude Raynaut

Resumo: Este artigo reflete a respeito da configuração dos perfis de sujeito trazidos e transformados por Alice através do Espelho a partir das interações com as personagens daquele mundo e sua relação com as características do espaço em que estão inseridos. Através dos estudos de Stuart Hall sobre identidade, do modo fantástico, da cadeia de negações de Tomáz Tadeu da Silva, as noções espaciais de Deleuze e Guattari e de Foucault, foi possível estabelecer uma reflexão que auxilia na compreensão dos efeitos de sentido que tais configurações acarretam na obra do escritor Lewis Carroll, intitulada Alice through the looking glass, de 1871.

Palavras-chave: Identidade; Rizoma; Fantástico; Alice.

Resumen: Este artículo refleja sobre la configuración de los perfiles de sujetos traídos y transformados por Alice a través del espejo desde las interacciones con los personajes de aquel mundo y su relación con las características del espacio en que están insertados. Con los estudios de Stuart Hall a cerca de la identidad, del modo fantástico, de la cadena de negaciones de Tomáz Tadeu da Silva, las nociones espaciales de Deleuze y Guattari y de Foucault ha sido posible establecer una reflexión que ayuda en la comprensión de los efectos de sentido que tales configuraciones conducen en la obra del escritor Lewis Carroll Alice through the looking glass, de 1871.

Palabras clave: Identidad; Rizoma; Fantástico; Alice. 


\section{DA DIFICULDADE DE SE LIBERTAR DO ARAME FARPADO ${ }^{1}$}

Para iniciar é preciso tomar algumas precauções. Dizer/ comentar qualquer coisa sobre este lugar e seus habitantes pode incorrer em um erro terrível, já expressado por Gilbert K. Chesterton, em 1932, a respeito da edição comentada dos livros de Alice. Ele temia que a história de Alice "já tivesse caído sob as mãos pesadas dos acadêmicos e tivesse se tornado fria e monumental como um túmulo clássico." (CHESTERTON Apud GARDNER, 2002, p.7). Ora, de fato ela caiu nas mãos de muitos acadêmicos de diferentes especialidades, mas sabemos, por outro lado, da impossibilidade de torná-la um túmulo, já que reconhecemos a sua imortalidade e seus efeitos de sentido inesgotáveis. O contrário disso incutiria em um presente de aniversário detestável.

Alice se ilude, a princípio, ao pensar que a razão está em algo que é buscado. O sentido é o preenchimento, o todo, os significados que podemos concluir ao final do raciocínio, das pequenas jornadas, o objeto direto. Alguns passos dados e percebe que a razão está na própria busca, que muitas vezes é marcada pela ausência, pelo vazio. Para preencher a obra é preciso aceitar esta busca pela ausência, cuja configuração nos parece um paradoxo, mas só o é se partirmos de um

1 Título dado a um dos capítulos do livro Está ficando tarde demais (Rocco, 2004), do escritor italiano Antonio Tabucchi. 
pressuposto intransigente, inflexível e puramente gramatical que faz do verbo "buscar" um transitivo direto unicamente. Esta obra que é aqui objeto de reflexão, se apresenta de forma líquida, pra usar a metáfora de Zygmunt Bauman. Quando a observamos com alguma distância, temos a certeza de avistarmos uma forma, mas ao tentar agarrá-la, segurála, ela se desfaz, escorre por entre os dedos. Este breve artigo aceita este estado e reconhece a impossibilidade de enquadrá-la, classificá-la e, assim, assassiná-la.

Carroll escreve a Macmillan, editor do seu primeiro livro, em 24 de agosto de 1866:

Ainda precisarei de algum tempo, provavelmente, antes de empreender um novo projeto editorial. Já começo, contudo, a planejar uma espécie de sequência para Alice e, se algum dia meu plano se concretizar, pretendo consultálo logo de partida, de modo a encaminhar as coisas da melhor maneira possível desde cedo².

E se concretizou, Alice Through the looking glass foi publicada pela primeira vez no natal de 1871. Depois do estrondoso sucesso de Alice in Wonderland (1865), Charles L. Dodgson repensou o rumo de seus escritos e decidiu, depois

2 As informações sobre o contexto de seu lançamento constam na biografia de Lewis Carroll escrita por Morton N. Cohen, Record: 1998 - traduzida por Raffaella de Filippis - e na edição comentada publicada pela editora Jorge Zahar: 2002, traduzida por Maria Luiza X. de A. Borges. 
de muitos tratados matemáticos, se aventurar mais uma vez na literatura. Novamente com as ilustrações de John Tenniel, a obra foi um sucesso imediato.

Lewis Carroll e sua obra dispensam apresentações, este artigo tem por objetivo refletir sobre a configuração da noção de identidade e algumas de suas consequências na trama da obra intitulada Alice Through the looking glass (1871), seguida de uma breve análise do espaço e sua relação com esta configuração.

\section{O QUE SE DIZ E O QUE SE ENTENDE}

Há algum tempo, um novo debate tem movimentado a comunidade universitária, para a pesquisadora Eneida Maria de Souza, da Universidade Federal de Minas Gerais, ele se baseia "na antiga discussão sobre os efeitos que determinadas teorias estrangeiras provocam no campo da crítica literária." (1998). Esta movimentação e estes efeitos giram em torno das concepções de cultura, de crítica, de teoria e da própria literatura. Os Estudos Culturais trouxeram novas reflexões sobre a "inter, a trans e, até mesmo, a pós-disciplinaridade, nos discursos produzidos pela academia", nas palavras de Rachel Esteves Lima (2009). Na esteira destas discussões, consequentemente, também a identidade se torna, mais uma vez, foco de atenção. A 
obra literária de Lewis Carroll traz efeitos marcantes no que diz respeito à configuração da identidade/alteridade, já que estamos diante do insólito, do fantástico, do maravilhoso, do nonsense, do surreal.

Stuart Hall, em sua obra A Identidade Cultural na PósModernidade (2002), traz contribuições importantes sobre os conceitos de sujeito e identidade que permeiam o homem desde o lluminismo. Propõe, então, três concepções principais: sujeito do iluminismo, sujeito sociológico e sujeito pós-moderno, contemplando características que vão da modernidade à dita pós-modernidade. Como este artigo não propõe uma categorização intransigente, nem uma sistematização rígida, traços das três concepções interessa à discussão proposta.

Resumidamente, o sujeito do iluminismo é aquele que está centrado, dotado de razão, não necessita de interação, é independente. O sujeito sociológico está presente na modernidade e se forma no processo de interação com os outros, na socialização e, portanto, não é independente. Já o sujeito pós-moderno é, para Hall (2002), um sujeito em crise de identidade, já que não possui uma identidade fixa. Esta última concepção, mas não apenas ela, dialoga com a noção de identidade proposta por Silva. 
Tomaz Tadeu da Silva, professor e pesquisador brasileiro, evidencia, amparado pelos estudos de Jacques Derrida, a cadeia de negações na qual a identidade está inserida. Para Silva (2000) a identidade está intrinsecamente relacionada à linguagem que, além de construir, omite e/ou evidencia as questões da diferença. Segundo Silva se a identidade é o que somos, a diferença é o que o outro é, nas palavras do autor: "A afirmação 'sou brasileiro', na verdade, é parte de uma extensa cadeia de negações, de expressões negativas de identidade, de diferenças. Por trás da afirmação 'sou brasileiro' deve-se ler: 'não sou argentino', 'não sou chinês' [...]." (2000, p.75). Isso equivale dizer que, nesta perspectiva, a identidade e a diferença são inseparáveis e, da mesma forma, dizer "ela é chinesa" significa dizer "ela não é argentina", "ela não é japonesa" etc., incluindo a afirmação de que "ela não é brasileira", isto é, que ela não é o que eu sou. Neste ponto de vista não tomamos o que somos como referência para avaliar o que não somos, pelo contrário, tomamos o que não somos para avaliar o que somos.

Além dessas concepções de sujeito propostas por Hall e desta cadeia de negações proposta por Silva, também algumas considerações de Gilles Deleleuze e Félix Guattari, de sua obra Mil Platôs (1995), cujas noções de "rizoma e 
"devir" permeiam muitos textos de autores dos chamados Estudos Culturais, interessará a esta reflexão. No volume 1 de Mil Platôs, os autores discutem a noção de "rizoma", ela está relacionada ao conceito de rizoma vindo da botânica, que prevê que as plantas possuem brotos que podem se ramificar em qualquer ponto e transformar-se em bulbo ou tubérculo, independente da localização da planta. O rizoma possui alguns princípios, já que delimitá-lo não o explicaria em hipótese alguma, dentre eles o princípio da multiplicidade, nas palavras dos autores:

Uma multiplicidade não tem nem sujeito
nem objeto, massomente determinações,
grandezas, dimensões que não podem
crescer sem que mude de natureza. Os
fios da marionete, considerados como
rizoma ou multiplicidade, não remetem à
vontade suposta una de um artista ou de
um operador, mas à multiplicidade das
fibras nervosas que formam por sua vez
uma outra marionete seguindo outras
dimensões conectadas às primeiras.
(1995, p.16).

Esta noção de multiplicidade, de rizoma, possibilita uma abordagem que caracteriza, sem delimitar, de acordo com a proposta deste artigo.

Apresentadas as principais noções que contribuirão para esta reflexão, vamos à ela. 


\section{3. "SE ERA ASSIM, PODIA SER; [...] COMO NÃO É, NÃO É. ISTO É LÓGICO."}

Diferente do primeiro livro, Alice in Wonderland ${ }^{3}$ (1865), a Alice de Through the looking glass (1871) enfrenta outros conflitos, além de se posicionar de maneira diferente. No início da história, nos deparamos com uma personagem centrada de razão, Alice repreende a sua gata, filhote de Dinah:

"Oh, sua coisinha travessa!" exclamou Alice, agarrando-a e dando-lhe um beijinho para fazê-la entender que estava frita. "Francamente, a Dinah devia ter lhe ensinado maneiras melhores! Você devia, Dinah, sabe que devia!" acrescentou, com um olhar de censura para a gata velha e falando no tom mais zangado de que era capaz... (CARROLL, 2002, p.134) ${ }^{4}$.

Ao repreender a gata, Alice parte de pressupostos que configuram o que é para si o errado ou o certo. A afirmação "você devia" oculta uma série de outras afirmações e negações, Alice diz isso e apresenta toda a composição de sua postura como sujeito naquele momento. Ou seja, quando a protagonista diz "você devia" ela diz também tudo que "não devia", delimitando, assim, a sua escolha e suas eliminações.

3 A este respeito, a dissertação de mestrado Um mergulho profundo: a alter-ação de Alice através do fantástico (2013) traz a configuração da identidade/alteridade de Alice no país das maravilhas.

4 Para este artigo, utilizarei a tradução de Maria Luiza X. de A. Borges. 
Esse modo de se posicionar, neste instante, dialoga com as características do sujeito iluminista apresentado por Hall. Embora ela assuma uma postura iluminista ao afirmar claramente categorias do que se deve ou não fazer, sua identidade não é algo acabado, formado, pronto. No decorrer de sua aventura, esta configuração se altera.

Quando analisamos o efeito que esta postura iluminista provoca, já nos deparamos com outra configuração. Claramente, Alice, repete o que ouve dos adultos em sua volta, suas ordens, seus ensinamentos de etiqueta, sua moral. No decorrer de todo o livro, este tom irônico está presente através das implicantes ordens que Alice costuma dar às outras personagens e, igualmente, receber delas:

"Oh! Por favor, não faça estas caretas, meu caro! [...] e não fique com a boca tão escancarada! As cinzas vão entrar todas nela...". (CARROLL, 2002, p.142).

"São três faltas, Kitty, e você não foi castigada por nenhuma delas. Sabe que estou acumulando todos os seus castigos para daqui a duas quarta-feiras...". (CARROLL, 2002, p.135)

"Se não calarem a boca, eu as colho!" (CARROLL, 2002, p.151).

"Já está na hora de você responder", disse a Rainha, olhando seu relógio; "abra um pouco mais a boca quando fala, e diga sempre 'Vossa Majestade'". (CARROLL, 2002, p.154). 
Em uma época em que crescer era coisa seríssima e em que as crianças muito pouco brincavam e se divertiam, e ficavam mais trancafiadas em casa com suas babás, os livros direcionados ao público infanto-juvenil, que já existiam, traziam uma linguagem simples, uma moral que apontava para os "bons costumes" e ao temor diante dos maus caminhos, uma tradição puritana. Nas palavras de Cohen: "Os livros de Alice se contrapõem cabalmente a essa tradição, destroem-na e oferecem à criança vitoriana algo mais leve e mais empolgante. Acima de tudo, esses livros não têm uma moral." (1998, p.179) E segue: "[...] Ao banir a seriedade, Charles rema na contracorrente dos livros ameaçadores tradicionalmente impostos às crianças". (1998, p.181). Seu contexto de publicação envolve uma ruptura e não é diferente com a própria Alice no contexto da diegese.

No capítulo 4, quando Alice encontra os desajeitados irmãos Tweedledum e Tweedledee, fica bastante evidente a ironia em relação às normas de etiqueta: “'Você fez tudo errado!' exclamou Tweedledum. 'A primeira coisa numa visita é dizer 'Como vai?' e dar um aperto de mão!'”. (CARROLL, 2002, p.174). Depois desta conversa, ela mesma reflete sobre as regras de etiquetas: "Alice não sabia como entabular uma conversa com pessoas com quem acabara de 
dançar. 'Não caberia dizer 'Como vai você?' agora', pensou com seus botões; 'de algum modo, parece que fomos além desse ponto'." (CARROLL, 2002, p.175).

Alice, no início, está diante de sua gata e seu processo de interação se dará, quase todo, com criaturas nãohumanas. Mas o que o mundo do espelho acrescenta é a antropomorfização. Diferente de sua gata, as criaturas do espelho Ihe questionam e causam estranhamento à ela, menos por serem criaturas antropomorfas que pelo ato de questionarem seus posicionamentos. Quando Alice entra no Jardim das Flores e descobre que elas podem falar, não gosta nada das críticas que recebe e tenta atingi-las de alguma forma: "Não gostando de ser criticada, Alice começou a fazer perguntas: 'Não sentem medo às vezes de ficar plantados aqui fora, sem ninguém para cuidar de vocês?'” (CARROLL, 2002, p.150). O fato dos Lírio-tigres falarem já seria o suficiente para que ela hesitasse, mas Alice já conversava com seus animais de estimação e, portanto, isso estaria mais para um desejo de criança realizado. O motivo de seu estranhamento no decorrer do livro é derivado da própria interação, do ato de socializar e de suas implicações.

Depois da irritação com as críticas do Lírio-tigre, a protagonista encontra uma outra forma de se afirmar diante 
das flores: “'Não faz mal!' Alice disse num tom apaziguador; e curvando-se para as margaridas, que estavam recomeçando naquele instante, sussurrou: 'Se não calarem a boca, eu as colho!'” (CARROLL, 2002, p.151), depois de alguns instantes, reitera: "Como é possível que vocês todos possam falar tão bem?' Disse Alice, na esperança de melhorar o humor dele com um elogio." (p.152). Como as criaturas do mundo do espelho respondem à menina, ela acaba percebendo as reações que provoca com suas ordens e ameaças e tenta melhorar a relação. Passa, assim, de um sujeito iluminista para um sociológico que leva em conta, portanto, os resultados da interação. Mas esta transição não é sistemática.

A irritação provocada algumas vezes em Alice é devido à inversão da lógica que está habituada, já que está no país através do espelho onde tudo é invertido. As afirmações das personagens são o contrário das suas:

Alice se sentara à margem de um riachinho, com o grande prato sobre os joelhos, e serrava diligentemente com a faca. "Isso é muito irritante!" disse, em resposta ao Leão (estava ficando perfeitamente acostumada a ser chamada de "o Monstro"). "Já cortei várias fatias, mas elas sempre se juntam de novo!"

"Você não sabe lidar com bolos do Espelho", observou o Unicórnio. 


$$
\begin{aligned}
& \text { "Primeiro sirva-o e depois corte-o." } \\
& \text { (CARROLL, 2002, p.222). }
\end{aligned}
$$

Ou quando tenta matar a sua sede ao lado da Rainha: "'Estou muito satisfeita de estar aqui... só que estou com tanto calor e com tanta sede!' 'Sei do que você gostaria!' disse a Rainha bondosamente, tirando uma caixinha do bolso. 'Aceita um biscoito?"' (CARROLL, 2002, p.158). Este efeito contrário, contribui para o nonsense que permeia toda a obra, e que à primeira vista, parece não fazer sentido algum, mas faz sentido contrário. 0 nonsense está relacionado a uma conduta contrária ao bom senso e à lógica comumente entendida: "O não-senso é ao mesmo tempo o que não tem sentido, mas que, como tal, opõese à ausência de sentido, operando a doação de sentido. E é isso que é preciso entender por non-sense." (DELEUZE, 1998, p.74). O inverso deste efeito também é verdadeiro, coerentemente com o mundo do Espelho, o nonsense atribui aos diálogos à falta de compreensão com a qual Alice se irrita, já que está no ângulo oposto ao seu habitual. Não apenas oposto, mas em vários outros ângulos que está entre o seu e o oposto.

Ao passar a considerar os efeitos que sua fala causa em seu interlocutor, Alice também passa a se reconsiderar. Sempre com a interferência das outras personagens e do espaço, que será discutido mais adiante. Depois de correr muito para ficar no mesmo lugar, a Rainha adverte antes que Alice siga: 
“...e lembre-se de quem você é.” (CARROLL, 2002, p.159). Um ótimo conselho para quem, momentos depois, se perderia na Oitava Casa, no bosque onde as coisas não têm nome:

“'Então, no fim das contas a coisa
realmente aconteceu! E agora, quem
sou eu? Vou me lembrar, se puder!
Estou decidida'. Mas estar decidida não
ajudou muito, e tudo que conseguiu
dizer, depois de quebrar a cabeça, foi: 'L,
eu sei que começa com L!'”. (CARROLL,
2002, p.169).

Stuart Hall apresenta uma concepção de sujeito, chamada por ele de pós-moderno, a qual é apontada como "não tendo uma identidade fixa, essencial ou permanente." (HALL, 2006, p.12). A estudiosa Kathryn Woodward (2000) propõe: “Existe uma crise de Identidade?", e responde: "Quase todo mundo fala agora sobre 'identidade'. A identidade só se torna um problema quando está em crise, quando algo que se supõe ser fixo, coerente e estável é deslocado pela experiência da dúvida e da incerteza." (Apud MERCER, 1990, p.4), ou como a "perda de um sentido de si" como apontou Hall (2006, p.9). Alice, quando entra no bosque, perde a referência que continha as informações sobre quem é, neste caso, seu nome, que delimita seu lugar no mundo. Este esquecimento gera incerteza e dúvidas, de forma a dialogar com as características deste sujeito pós-moderno proposto por Hall. 
Alice, depois de percorrido alguma distância dentro do Espelho e transitado de uma postura iluminista para uma sociológica e para uma pós-moderna, não necessariamente nesta ordem e, tampouco sem retornar a uma ou a outra, começa a, cada vez mais, se deparar com situações que parecem refletir sobre os avessos. Como quando a menina está conversando com o Rei Branco, no capítulo 7, ele pede para que Alice olhe para a estrada e veja se avista algum soldado: “'Ninguém à vista', disse Alice. 'Só queria ter olhos como esses', observou o Rei num tom irritado. 'Ser capaz de ver Ninguém! E à distância! Ora, o máximo que eu consigo é ver pessoas reais, com esta luz'". (CARROLL, 2002, p.214). Os habitantes daquele mundo levam também em consideração aquilo que para ela parece ser tão natural, de forma a parecer absurdo para eles. Temos aqui uma situação inversa. A própria Rainha atenta a menina para isso: “'Não a entendo', disse Alice. 'É horrivelmente confuso!' 'É isso que dá viver às avessas', disse a Rainha com doçura: 'sempre deixa a gente um pouco tonta no começo..."' (CARROLL, 2002, p.189).

Uma outra interação marcante, na qual também encontramos a diferente lógica dos habitantes do Espelho, é quando Alice se reencontra com a Rainha Vermelha e com a Rainha Branca. Esta última, em uma conversa sobre 
trovão, diz: "tivemos tal tempestade terça-feira passada... quero dizer, uma da última série de terças-feiras." Alice achou aquela afirmação bastante estranha e disse: "No nosso país [...] os dias da semana vêm um de cada vez." (CARROLL, 2002, p.246). A Rainha Vermelha interfere com sua opinião, dizendo ser lastimável esta maneira de fazer as coisas, afinal, no Espelho "geralmente os dias e as noites vêm em dois ou três por vez, e no inverno de vez em quando temos até cinco noites juntas... para aquecer mais, sabe." (CARROLL, 2002, p.246).

Ocorre, também, que as "não afirmações", as coisas ocultas nas afirmações, eliminadas por elas, ganham luz no Espelho e, com isso, novas considerações precisam ser feitas, o que reflete na caracterização da identidade. Afinal, levar em consideração as suas negações implícitas nas afirmações é o oposto da concepção tradicional iluminista, na qual apenas as afirmações são importantes. Estas premissas são levadas a cabo no capítulo 6, ao interagir com Humpty Dumpty.

O pedante ovo antropomórfico desconstrói todas as certezas de Alice e a coloca em uma situação de constante desconforto. Ele utiliza toda a sua lógica que contempla também todas as negações escondidas nas afirmações que se apresentam óbvias para Alice, deixando-a completamente 
confusa. O nonsense de Humpty Dumpty é algo mais indignante para a menina, de tal forma que invalida todas as suas tentativas de interação amigável.

Já de saída, a garotinha sai com uma ofensa e compra a antipatia de Humpty Dumpty: "'Parece um ovo sem tirar nem pôr!' disse alto, com as mãos prontas para segurálo, pois temia que caísse a qualquer momento. 'É muito irritante', Humpty Dumpty disse após um longo silêncio, sem olhar para Alice enquanto falava, 'ser chamado de ovo... muito!'”. (CARROLL, 2002, p.199). Alice tenta, logo em seguida, amenizar a tensão com algum elogio, mas ele é implacável. Além disso, o fato de ele não olhar para ela enquanto fala, como manda a regra convencional, a deixa ainda mais irritada. Como se não bastasse, ele emenda: “'Certas pessoas', disse Humpty Dumpty, desviando os olhos dela como sempre, 'parecem não ter mais juízo que um bebê!'” (CARROLL, 2002, p.199).

Este episódio nada convencional para a menina se torna mais um jogo que uma conversa, de modo que as posturas identitárias como sujeito, repensadas até aquele momento, não parecem servir à situação. Neste jogo de linguagem, Alice precisa também jogar consigo mesma e com suas convenções: 


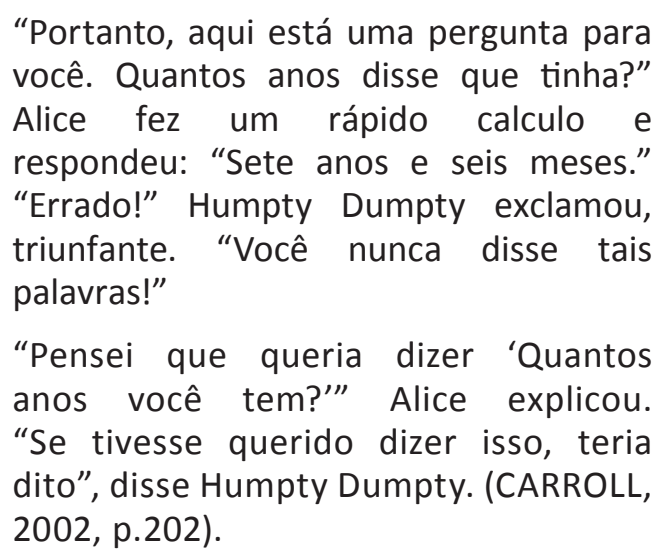

Este jogo que ele estabelece com a menina, além de desestabilizá-la, chama a atenção para o que está sendo dito, ao contrário do que pode parecer em um primeiro momento. O efeito que ele causa é fazer com que Alice dê atenção a cada partícula que formam as frases que diz, nenhuma está neutra, e cada uma traz consigo uma carga de significados. Algo puramente lógico, matemático.

Todas estas alternâncias em sua postura como sujeito, sobre as quais refleti brevemente, não ocorrem de modo aleatório. Além de estarem relacionadas às rupturas causadas pelos habitantes, já que estes andam na contramão daquilo que Alice julga habitual, os habitantes estão profundamente relacionados ao espaço em que estão inseridos. A configuração do espaço é construída através do modo fantástico e é um dos fios condutores desta narrativa. 


\section{UM TABULEIRO DE MULTIPLICIDADES}

Para Deleuze e Guattari “[...] não se perguntará nunca o que um livro quer dizer, significado ou significante, não se buscará nada compreender num livro, perguntar-se-á com o que ele funciona." (1995, p.12). O funcionamento do mundo através do Espelho se dá por meio do modo fantástico que configura o espaço de maneira rizomática e, como vimos anteriormente, conduz as posturas dos sujeitos naquele país.

Para Ceserani, estudioso e crítico literário italiano, em sua obra O Fantástico (2006), o fantástico se trata de um modo que

[...] teve suas raízes históricas precisas e se situou historicamente em alguns gêneros e subgêneros, mas que pôde ser utilizado - e continua a ser, com maior ou menor evidência e capacidade criativa em obras pertencentes a gêneros muito diversos. (p.12).

O autor afirma que a produção literária misturou-se a outros gêneros literários e alguns elementos muito presentes, como a autorreflexão, a solução estética, o fabuloso, o gosto pelo grotesco, pareceram emergir em um ou outro texto (p.90), até se desdobrar nas várias características do modo fantástico. É importante, ainda, apontar que este modo fantástico introduzido no começo do século XIX demonstrou vitalidade, "foi um componente relevante daquilo que 
chamamos a literatura da 'modernidade', e ainda hoje ocupa um lugar central na imaginação literária e, ainda mais, na não literária." (CESERANI, 2006, p.93).

Em outras palavras, estamos falando de uma categoria, de um modo literário, que abarca o insólito. Os livros de Alice abarcam uma tradição que remonta ao épico clássico, passa pelos contos de horror do século XVII e segue obras produzidas ao longo do século $X^{5}$.

O funcionamento do Espelho é rizomático, conforme princípio de multiplicidade apresentado no início deste artigo, pois se conecta sem "pontos ou posições" como numa estrutura, nas palavras de Deleuze e Guattari, o que encontramos são somente linhas. Vejamos o que ocorre com o espaço neste fragmento:

\begin{abstract}
"Sabe remar?" a Ovelha perguntou, estendendo-Ihe um par de agulhas de tricô enquanto falava. "Sei, um pouco... mas não no seco... e não com agulhas..." Alice estava começando a dizer, quando, de repente, as agulhas viraram remos em suas mãos e ela descobriu que estavam num barquinho, deslizando entre ribanceiras - de modo que só lhe restava remar o melhor que podia. (CARROLL, 2002, p.195)
\end{abstract}

5 Esta afirmação tem por base uma investigação já realizada no ano de 2010 como trabalho de conclusão do curso de Letras Português/Espanhol na Universidade Estadual de Ponta Grossa. $\mathrm{O}$ artigo já tratava da presença de uma tradição fantástica dentro dos livros de Carroll: Alice in Wonderlandand Through the Looking-Glass (1865 - 1872). Disponível em http://periodicos.ufes. $\mathrm{br} / \mathrm{reel} / \mathrm{article} / \mathrm{view} / 6172 / 4510$ 
O sobrenatural, o fantástico, permite que a estrutura espacial seja como um mapa: "é aberto, é conectável em todas as suas dimensões, desmontável, reversível, suscetível de receber modificações constantemente." (DELEUZE e GUATTARI, 1995, p.22). Neste fragmento das aventuras de Alice, o espaço se conecta com outro completamente diferente daquele e sem uma aparente estrutura "lógica", os objetos se transformam em outros à medida que se faz necessário, à medida que a linha da interação que estabelece pede que as agulhas se transformem em remos e o local onde estavam em um barco.

Foucault afirma que a heterotopia "tem o poder de justapor em um só lugar real vários espaços, vários posicionamentos que são em si próprios incompatíveis" (2001, p.418), e caracteriza, ainda, a heterotopia de desvio: "aquela na qual se localizam os indivíduos cujo comportamento desvia em relação à média ou à norma exigida" (2001, p.416). Ora, isso ajuda a refletir sobre a configuração espacial do Espelho, na medida em que os espaços se justapõem de maneira "desviada", pois se encontram neste novo espaço várias individualidades que transgridem a regra comportamental convencional. Esta justaposição, levada ao pé da letra, ocorre, como vimos no exemplo anterior, através do modo fantástico. 
Alice salta o primeiro dos seis riachinhos e surge dentro de um vagão de trem:

[...] desceu o morro correndo e saltou por sobre o primeiro dos seis riachinhos. "Passagens, por favor!" disse o Guarda, enfiando a cabeça pela janela. Num instante estavam todos empunhando passagens: eram mais ou menos do tamanho das pessoas e pareciam encher completamente o vagão. (CARROLL, 2002, p.162)

O espaço se liga a outro completamente diferente. Como é a própria espacialidade do mundo onírico. Isso se sucede no decorrer de todo o enredo. Esta multiplicidade, estas ligações de um espaço para o outro constitui parte do que é a própria noção de rizoma.

A lógica dos encontros de Alice no Espelho também parece ser rizomática, na medida em que a conexão entre ela e as personagens não acontece seguindo uma linha sistemática, os encontros, assim como os caminhos e os atalhos são em forma de mapa, como vimos: "O mapa não reproduz um inconsciente fechado sobre ele mesmo, ele o constrói. Ele contribui para a conexão dos campos." (DELEUZE e GUATTARI, 1995, p.22).

Da maneira como Alice escorrega pelos espaços múltiplos, se depara com as distintas personagens. Elas estão 
relacionadas a estas espacialidades, pois se movem nelas, são construídas por elas e as constroem, se retroalimentam. Os espaços rizomáticos, as heterotopias de desvio, geram algumas necessidades, como a da Rainha Vermelha de correr muito para permanecer no mesmo lugar, que causa, como vimos, estranhamento a Alice, pois é exatamente o contrário da sua regra habitual. E não apenas dela, como a do leitor, gerando assim um efeito de leitura parecido com o que a própria personagem vivencia.

O modo fantástico envolve uma forma de configuração através de uma transgressão da norma. Júlio Cortazar, escritor e crítico argentino, em sua Valise de Cronópio, diz que o fantástico "se opõe a esse falso realismo que consiste em crer que todas as coisas podem ser descritas e explicadas como dava por assentado o otimismo filosófico e científico do século XVIII [...]." (1993, p.148). Ceserani também toca em uma reflexão que traz o modo fantástico como uma transgressão deste pensamento científico do século XVIII,

[...] é necessário pensar, no que se refere ao sistema literário, na fortíssima carga de renovação operada pela literatura romântica e à geral reestruturação dos gêneros literários ocorrida entre os séculos XVIII e XIX. Em particular, é preciso pensar no florescimento, 
na Inglaterra, do romance gótico de Horace Walpole, Mathew Lewis, William Beckford, Ann Radclife e Mary Shelley. (2006, p.89).

O próprio fantástico, aquele que mora na hesitação, do qual nos fala Todorov, vai muito além de um pretexto:

Ao lado da censura institucionalizada, existe uma outra, mais sutil e mais geral: a que reina na própria psique dos autores. A condenação de certos atos pela sociedade provoca uma condenação que se exerce dentro do próprio indivíduo, constituindo-se assim para ele em proibição de abordar certos temas tabus. Mais do que um simples pretexto, o fantástico é um meio de combate contra uma e outra censura: os desmandos sexuais serão aceitos por qualquer espécie de censura se forem inscritos por conta do diabo. (TODOROV, 2010, p.167).

Ou seja, o fantástico permite considerar muitas discussões e transgredir muitas normas, mas isso exige uma postura de leitura, exige uma visão de mundo. O autor segue comentando ainda sobre a transgressão de tabus que alguns personagens trazem consigo, por exemplo, o psicótico, o louco, o criminoso são todos trancafiados e condenados severamente pela sociedade, assim como as drogas, pois suscitam modos de pensamentos incompreensíveis e são 
todos julgados culpados (2010, p.168), e, desta forma, a "introdução de elementos sobrenaturais é um recurso para evitar esta condenação." (TODOROV, 2010, p.168). Carpentier, na conhecida introdução ao seu livro El reino de este mundo, também aponta para esta transgressão, para o valor do olhar trazido, desta vez, pelo maravilhoso:

Mas muitos se esquecem, disfarçandose de magos, que o maravilhoso começa a ser de maneira inequívoca quando surge de uma alteração da realidade (o milagre), de uma revelação privilegiada da realidade, de uma iluminação não habitual ou singularmente favorecedora das inadvertidas riquezas da realidade, de uma ampliação das escalas e categorias da realidade percebidas com intensidade particular em virtude de uma exaltação do espírito que o conduz a um modo de estado limite. (2003, p.6).

O modo fantástico, portanto, traz intrinsecamente uma transgressão da regra e, por que não, uma inversão. O espaço do Espelho segue a lógica invertida e matemática do reflexo. Quando levantamos a mão esquerda no espelho, o reflexo levanta a direita. Esta inversão, logicamente, conduz as espacialidades, mas não apenas ela, como vimos, a justaposição, por exemplo, também as caracterizam. De maneira diretamente proporcional à formação da espacialidade do mundo do Espelho está a caracterização 
dos sujeitos e de suas identidades. Quando Alice entra em contato com esta configuração, ela também se torna múltipla, rizomática, "desviada", inevitavelmente.

\section{5. ...E AFINAL DE CONTAS}

A reflexão estabelecida aqui, teve por objetivo pensar sobre aquilo que Gama-Khalil chama de "alargar o enfoque analítico" (2013, p.30) sobre a literatura que traz o elemento insólito, ou seja, encontrar, paradoxalmente, os desvios necessários para compreender de que maneira ela se constrói e que efeitos esta construção desencadeia.

A configuração das noções de sujeito trazidas por Alice e transformada por ela através das interações estão profundamente relacionadas com toda a caracterização da obra, um aspecto em particular: o espaço. A elasticidade do espaço concede aos sujeitos que nele estão a mesma elasticidade identitária. Não são categorizáveis, não são passíveis de sistematizações, ou então, o espaço desapareceria.

As transições pelas quais Alice passa como sujeito de um discurso no decorrer de sua trajetória naquele mundo tem como um dos fios condutores a interação com as personagens que a desafiam ao transgredir suas regras habituais e o espaço, também transgressor, que abriga estas interações. 
Ela está acostumada à rigidez das coisas, à formalidade cobrada das crianças. Alice estranha quando estas regras desaparecem. O efeito que o espelho the causa, as frequentes reinvenções de si e de suas concepções, são muito mais pela inversão que pelos "absurdos" de ver uma flor falar ou um ovo linguista.

Por fim, o efeito de sentido de um espaço rizomático só poderia ser o de sujeitos múltiplos e o de leituras múltiplas. Esta é apenas uma delas, a ponte que a conecta a outras é uma variável que oculta todas as outras possibilidades não evidenciadas aqui. Dizer isso é também atribuir valor ao que se oculta na cadeia de negações que me levou a estas afirmações.

\section{REFERÊNCIAS}

BAUMAN, Zygmunt (2005). Identidade: entrevista a Benedetto Vecchi. Carlos Alberto Medeiros (Trad.). Rio de Janeiro: Jorge Zahar Ed.

CARROLL, Lewis (2009). Alice's adventures in wonderland and through the looking-glass. Londres: Penguin.

. (2002). Alice: edição comentada. Introdução e notas, Martin Gardner. Maria Luiza X. de A. Borges (Trad.). Rio de Janeiro: Jorge Zahar. CESERANI, Remo (2006). O fantástico. Nilton Cezar Tridapalli (Trad.). Curitiba: UFPR.

COHEN, N. Morton (1998). Lewis Carroll: uma biografia. Raffaela de Filippis (Trad.). Rio de Janeiro: Record.

CORTAZAR, Júlio (1993). Valise de cronópio. Davi Arrigucci Jr; João Alexandre Barbosa (Trad). São Paulo: Perspectiva. 
DELEUZE, G.; GUATTARI, F. (1995). Mil platôs: capitalismo e esquizofrenia. Vol.1 Aurélio Guerra Neto e Célia Pinto Costa (Trad.). São Paulo: Editora 34. . (1997). Mil platôs: capitalismo e esquizofrenia.Vol.4 Suely Rolnik (Trad.). São Paulo: Ed. 54.

DELEUZE, Gilles (1974). "Quinta série: do sentido". In: Lógica do sentido. Luiz Roberto Salinas Fortes (Trad.). São Paulo: Perspectiva.

. (1974). "Décima primeira série: do não-senso". In: Lógica do sentido. Luiz Roberto Salinas Fortes (Trad.). São Paulo: Perspectiva.

HALL, Stuart (2002). A identidade cultural na pós-modernidade. Rio de Janeiro: DP\&A.

HARVEY, David (1992). Condição pós-moderna. São Paulo: Edições Loyola. LIMA, Rachel Esteves (2009). "Os Estudos Culturais e a crise da universidade moderna". In: Revista Caderno de Estudos Culturais. Campo Grande, 1, p.63-72.

SILVA, Tomaz Tadeu (2000). "A produção social da identidade e da diferença". In: Identidade e diferença: a perspectiva dos estudos culturais. 10.ed. Petrópolis: Vozes, p.73-102.

SOUZA, Eneida Maria de (1998). "A Teoria em Crise". In: Revista Brasileira de Literatura Comparada, 4.

WOODWARD, Kathryn (2000). "Identidade e diferença: uma introdução teórica e conceitual”. In: SILVA, Tomaz Tadeu (Org. e Trad.). Identidade e diferença: a perspectiva dos estudos culturais. 10.ed. Petrópolis: Vozes. p.73-102.

Ana Carla Vieira Bellon. Graduação em Letras e Mestrado em Estudos Literários. Ana Carla Vieira Bellon. Graduação em Letras pela Universidade Estadual de Ponta Grossa, Mestrado em Estudos Literários pela Universidade Federal do Paraná e Doutoranda em Literatura Comparada pela Universidade do Estado do Rio de Janeiro. Docente no Ensino Básico e Superior. Atualmente pesquisadora da obra fotográfica e literária de Lewis Carroll a partir do insólito 
ficcional. Possui artigos publicados principalmente nos seguintes temas de interesse: Literatura e Cinema; Literatura Insólita; Literatura e Alteridade; Literatura e Filosofia; Literatura e Fotografia; Teoria Literária. Email: acvbellon@hotmail.com.

Recebido em 13 de janeiro 2016

Aprovado em 14 de março 2016 